\title{
Effectiveness of workplace social distancing measures in reducing influenza transmission: a systematic review
}

\author{
Faruque Ahmed", Nicole Zviedrite and Amra Uzicanin
}

\begin{abstract}
Background: Social distancing is one of the community mitigation measures that may be recommended during influenza pandemics. Social distancing can reduce virus transmission by increasing physical distance or reducing frequency of congregation in socially dense community settings, such as schools or workplaces. We conducted a systematic review to assess the evidence that social distancing in non-healthcare workplaces reduces or slows influenza transmission.
\end{abstract}

Methods: Electronic searches were conducted using MEDLINE, Embase, Scopus, Cochrane Library, PsycINFO, CINAHL, NIOSHTIC-2, and EconLit to identify studies published in English from January 1, 2000, through May 3, 2017. Data extraction was done by two reviewers independently. A narrative synthesis was performed.

Results: Fifteen studies, representing 12 modeling and three epidemiological, met the eligibility criteria. The epidemiological studies showed that social distancing was associated with a reduction in influenza-like illness and seroconversion to 2009 influenza A (H1N1). However, the overall risk of bias in the epidemiological studies was serious. The modeling studies estimated that workplace social distancing measures alone produced a median reduction of $23 \%$ in the cumulative influenza attack rate in the general population. It also delayed and reduced the peak influenza attack rate. The reduction in the cumulative attack rate was more pronounced when workplace social distancing was combined with other nonpharmaceutical or pharmaceutical interventions. However, the effectiveness was estimated to decline with higher basic reproduction number values, delayed triggering of workplace social distancing, or lower compliance.

Conclusions: Modeling studies support social distancing in non-healthcare workplaces, but there is a paucity of well-designed epidemiological studies.

Systematic review registration number: PROSPERO registration \# CRD42017065310.

Keywords: Influenza, Distancing, Community mitigation, Non-pharmaceutical, Systematic review, Telework, Workplace

\section{Background}

Influenza pandemics occur when new influenza A viruses emerge that spread from person to person in an efficient and sustained way. Over the past 100 years, the clinical severity of influenza pandemics has ranged from moderate for the 2009 pandemic to very high for the 1918 pandemic [1]. The economic impact of the next influenza pandemic

\footnotetext{
* Correspondence: fahmed@cdc.gov

Community Interventions for Infection Control Unit, Division of Global Migration and Quarantine, Centers for Disease Control and Prevention (CDC), Atlanta, GA, USA
}

(c) The Author(s). 2018 Open Access This article is distributed under the terms of the Creative Commons Attribution 4.0 International License (http://creativecommons.org/licenses/by/4.0/), which permits unrestricted use, distribution, and reproduction in any medium, provided you give appropriate credit to the original author(s) and the source, provide a link to the Creative Commons license, and indicate if changes were made. The Creative Commons Public Domain Dedication waiver (http://creativecommons.org/publicdomain/zero/1.0/) applies to the data made available in this article, unless otherwise stated.

in the United States, in the absence of vaccination and other mitigation measures, has been estimated to be $\$ 71$ to $\$ 166$ billion [2]. A vaccine against a new pandemic virus might not be widely available for up to 6 months given current vaccine production technology [3]. The 2017 Update of the Pandemic Influenza Plan published by the US Department of Health and Human Services includes community mitigation measures, known also as nonpharmaceutical interventions (NPIs), that can be used before a pandemic vaccine is widely available [4]. The goals of community mitigation are to delay the influenza 
peak to buy time for the development and administration of a well-matched pandemic vaccine; reduce the peak number of daily influenza cases to decrease stress on the health-care system and to protect critical infrastructure (by reducing daily absenteeism rates); and reduce the overall number of influenza cases in order to decrease morbidity and mortality [3]. NPIs include personal protective measures, environmental measures, and community measures aimed at increasing social distancing. Social distancing can reduce virus transmission from infected persons to susceptible individuals by increasing physical distance between people or reducing frequency of congregation in socially dense community settings, such as schools or workplaces [3]. The US Pandemic Influenza Plan as well as the World Health Organization Public Health Research Agenda for Influenza have called for more research on the effectiveness, timing, and optimal implementation of social distancing measures in different community settings $[4,5]$. Research on the effectiveness of social distancing has focused on schools, most notably on pre-emptive school closures, for which systematic reviews have been published [6, 7].

Of the US civilian noninstitutionalized population aged $\geq 16$ years, about two-thirds participate in the labor force [8]. The influenza illness attack rate in the workplace in a severe pandemic can be over 20\% [1]. Contacts made in the workplace represent $20-25 \%$ of all weekly contacts, and influenza transmission in the workplace represents on average 16\% (range 9-33\%) of all transmissions [9]. Social distancing measures in non-healthcare workplaces can include increased use of telecommuting and remote-meeting options, staggered work hours, and spacing workers further apart [3]. The objective of this systematic review is to assess the evidence that social distancing interventions in non-healthcare workplaces, compared to no intervention, reduce or slow influenza transmission among workers and in the general population.

\section{Methods}

The protocol for this systematic review was registered on PROSPERO, an international prospective register of systematic reviews (ID \# CRD42017065310) [10]. The systematic review was conducted following the Preferred Reporting Items for Systematic Reviews and Meta-Analysis (PRISMA) statement (see Additional file 1) [11]. The inclusion criteria included randomized controlled trials, epidemiological studies, and modeling studies reporting results of social distancing interventions in non-healthcare workplaces. The exclusion criteria included the following: review articles, commentaries, and editorials; studies in animals; studies conducted in health-care, school, or university settings; and studies on workplace closure (workplace closure is not a recommended NPI [3]). Studies on generic social distancing that did not specifically mention workplace social distancing were also excluded. The primary outcomes of interest were the following: cumulative influenza attack rate (percentage of individuals in a given population who will get influenza illness); peak influenza attack rate; time to peak; lost workdays; and harms.

\section{Literature search strategy and study selection}

Electronic searches of the published and grey literature were conducted using MEDLINE, Embase, Scopus, Cochrane Library, PsycINFO, Cumulative Index to Nursing and Allied Health Literature (CINAHL), NIOSHTIC2, and EconLit to identify studies published in English during the period January 1, 2000, through May 3, 2017. The search terms are provided in PROSPERO [10]. Two reviewers (FA and NZ) independently identified eligible articles by screening titles and abstracts and reviewing full-text articles. The reference lists of included studies were examined to search for additional studies.

\section{Data extraction and risk of bias assessments}

Two reviewers (FA and NZ) extracted data independently from all included studies using a standard form that was piloted. Variables for which data were sought included the following: study dates, study design, predominant influenza strain, threshold for triggering social distancing, basic reproduction number $\left(R_{0}\right)$, population characteristics, type of intervention (including duration of intervention), comparator, type of outcome measures, setting, publication status, and funding source. Two reviewers (FA and NZ) independently assessed the quality of epidemiological studies using the Risk of Bias in Non-randomized Studies of Interventions (ROBINS-I) tool [12]. Risk of bias for each domain is classified into four categories: low (study is comparable to a well performed randomized trial), moderate (study is sound for a nonrandomized study but cannot be considered comparable to a well performed randomized trial), serious (study has some important problems), and critical (study is too problematic to provide any useful evidence on the effects of intervention). A particular level of risk of bias for an individual domain means that the overall risk of bias for the study is at least this severe. Any disagreements were resolved through discussion or a third reviewer (AU). The quality of modeling studies was not assessed.

\section{Data synthesis}

Percentage reductions were calculated using the following formula: Percentage reduction $=(($ Attack rate in the 
absence of intervention - Attack rate with intervention) /Attack rate in the absence of intervention) $\times 100$ [6]. A narrative synthesis was performed [13].

It was decided a priori to present results by basic reproduction number $\left(R_{0}\right)$, a measure of virus transmissibility. $R_{0}$ is defined as the average number of secondary cases produced by a typical infectious case in a fully susceptible population [14]. A reproduction number greater than 1 indicates that the infection will grow in the population, whereas a value less than 1 indicates that the infection will decline [14]. Higher $R_{0}$ values are associated with higher cumulative attack rates [15]. Factors that affect $R_{0}$ include the population contact rate, the probability of infection per contact, and the duration of illness. The results are presented using three $\mathrm{R}_{0}$ categories: $\leq 1.9 ; 2.0-2.4$; and $\geq 2.5$ [6]. The $R_{0}$ of the 1918 influenza pandemic was somewhat higher than those of the 1957, 1968, and 2009 pandemics, but the $R_{0}$ values of all four pandemics were estimated to be less than 1.9 [14]. The characteristics of influenza pandemics are unpredictable, and the higher $R_{0}$ categories provide estimates for an atypical pandemic.

\section{Results}

The selection of eligible studies is shown in the PRISMA flow diagram (Fig. 1). The database search identified 4743 records. After removal of duplicates, 3421 records were screened. Among the excluded studies, 10 included workplace closure and one did not include a "no intervention" comparator [16-26]. Fifteen studies, representing three epidemiological [27-29] and 12 modeling [30-40], met the inclusion criteria. Nine studies were from North America, four from Asia, one from Europe, and one from Australia (Appendix). The funding sources of the studies were government (10 studies), university (2 studies), research council (1 study), industry (1 study), and none/ unknown (1 study).

Social distancing measures in the epidemiological studies included segregation of persons into small subgroups and working from home (Appendix). These studies showed reductions in seroconversion to 2009 influenza A (H1N1), occurrence of influenza-like illness (ILI), and workplace attendance with severe ILI (which would result in reduced transmission) (Table 1). The overall risk of bias in the epidemiological studies was serious in two studies and critical in one study (Table 2). All three studies had moderate or serious risk of bias in the confounding domain, and two studies had moderate risk of bias in the outcome measurement domain. In addition, because the outcomes used in these studies were surrogates for influenza illness, the evidence was indirect [41].

Among the modeling studies, the most frequent workplace social distancing measure assessed was reduction in workplace contacts by $50 \%$ for the entire duration of the outbreak (Appendix). One study assessed the effect of extending the weekend. Several studies assessed the effect of combining workplace social distancing measures with other interventions, including school closure, community contact reduction, antiviral treatment and prophylaxis, and vaccination.

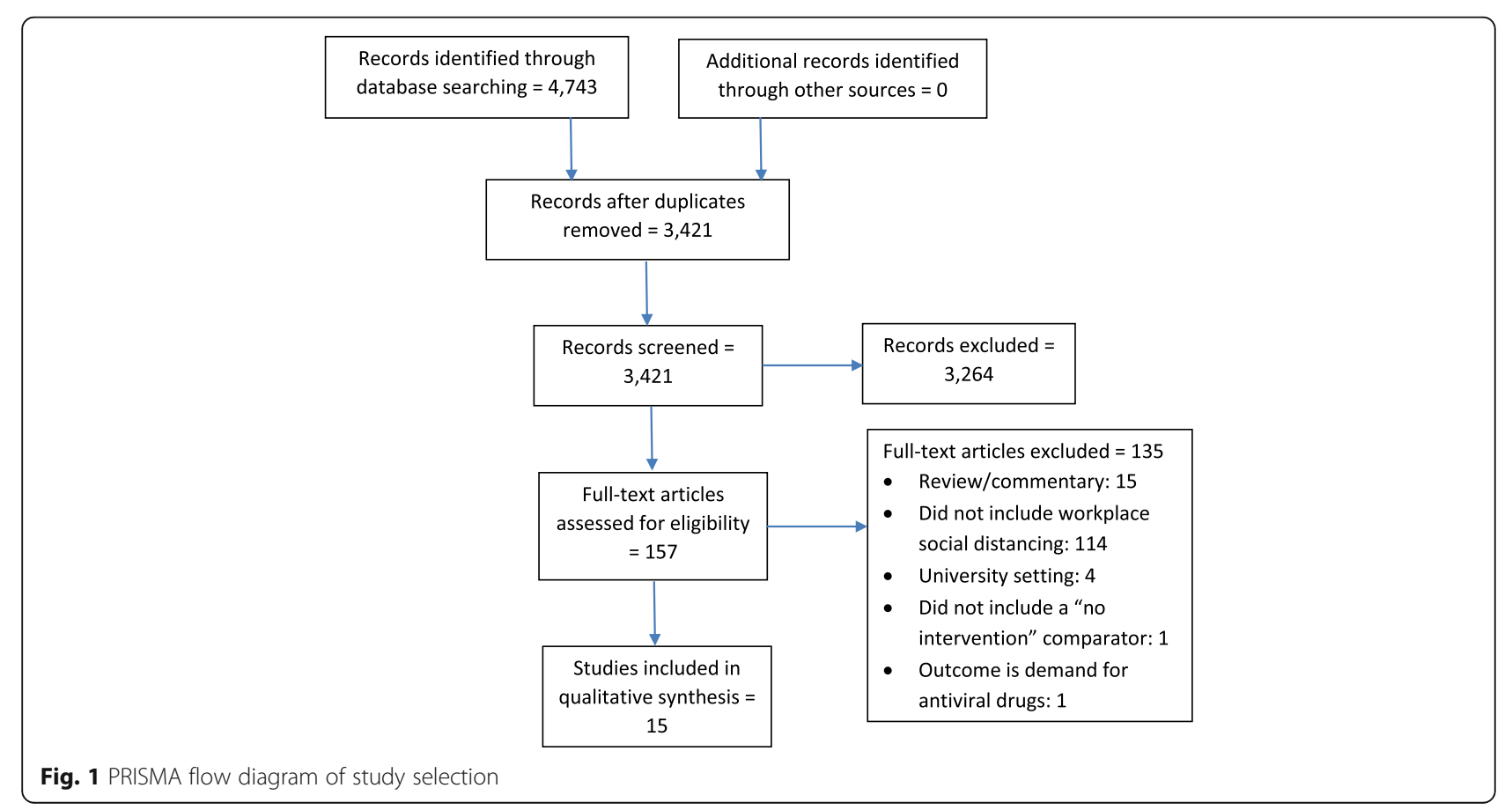


Table 1 Percentage reduction in cumulative influenza attack rate, 2000-2017

\begin{tabular}{|c|c|c|c|c|c|c|}
\hline \multirow[t]{2}{*}{ First author, year published } & \multirow[t]{2}{*}{ Country } & \multirow[t]{2}{*}{ Influenza strain } & \multirow[t]{2}{*}{ Intervention $^{\mathrm{b}}$} & \multicolumn{3}{|c|}{ Percentage reduction ${ }^{a}$} \\
\hline & & & & $\mathrm{R}_{0} \leq 1.9$ & $R_{0}=2.0-2.4$ & $R_{0} \geq 2.5$ \\
\hline \multicolumn{7}{|l|}{ Epidemiological studies $^{c}$} \\
\hline Rousculp, 2010 [27] & USA & $\begin{array}{l}\text { Seasonal influenza A(H3N2), 2007- } \\
2008\end{array}$ & Single & 20 & - & - \\
\hline Kumar, 2012 [28] & USA & 2009 influenza $\mathrm{A}(\mathrm{H} 1 \mathrm{~N} 1)$ pandemic & Single & 36 & - & - \\
\hline Lee, 2010 [29] & Singapore & 2009 influenza $\mathrm{A}(\mathrm{H} 1 \mathrm{~N} 1)$ pandemic & Multiple & 61 & - & - \\
\hline \multicolumn{7}{|l|}{ Modeling studies } \\
\hline Timpka, 2016 [30] & Sweden & Future pandemic strain & Single & $12^{d}$ & - & - \\
\hline Zhang, 2012 [31] & Singapore & Not reported & Single & 18 & - & - \\
\hline Mao, 2011 [32] & USA & $\begin{array}{l}\text { Seasonal scenario }\left(R_{0}=1.4\right) \text { and } \\
\text { a pandemic scenario }\left(R_{0}=2.0\right)\end{array}$ & Single & 82 & 23 & - \\
\hline \multirow[t]{2}{*}{ Xia, 2013 [33] } & China & 2009 influenza $\mathrm{A}(\mathrm{H} 1 \mathrm{~N} 1)$ pandemic & Single & - & - & - \\
\hline & & & Single + VAC & - & - & - \\
\hline \multirow[t]{2}{*}{ Milne, 2008 [34] } & Australia & Pandemic strain & Single & 28 & 13 & 7 \\
\hline & & & Multiple & 94 & 96 & 95 \\
\hline Milne, 2013 [35] & $\begin{array}{l}\text { Papua New } \\
\text { Guinea }\end{array}$ & Pandemic strain & Multiple & $63^{e}$ & - & - \\
\hline Miller, 2008 [36] & USA & $\begin{array}{l}\text { Influenza } \mathrm{A}(\mathrm{H} 3 \mathrm{~N} 2) \text { in population } \\
\text { with no prior immunity }\end{array}$ & Multiple & 88 & - & - \\
\hline \multirow[t]{3}{*}{ Andradottir, 2011 [37] } & Canada & 2009 influenza $\mathrm{A}(\mathrm{H} 1 \mathrm{~N} 1)$ pandemic & Multiple & 30 & - & - \\
\hline & & & $\begin{array}{l}\text { Multiple + } \\
\text { VAC }\end{array}$ & 61 & - & - \\
\hline & & & Multiple + AV & 73 & - & - \\
\hline \multirow[t]{2}{*}{ Perlroth, 2010 [38] } & USA & Not reported & Multiple & 77 & 38 & - \\
\hline & & & Multiple + AV & 90 & 71 & - \\
\hline \multirow[t]{2}{*}{ Halloran-Imperial/Pitt model, 2008 [39] } & USA & Future pandemic strain & Multiple & 73 & - & - \\
\hline & & & Multiple + AV & 83 & 70 & 53 \\
\hline \multirow[t]{2}{*}{ Halloran-UW/LANL model, 2008 [39] } & USA & Future pandemic strain & Multiple & 89 & - & - \\
\hline & & & Multiple + AV & 94 & 92 & 86 \\
\hline \multirow[t]{2}{*}{ Halloran-VBI model, 2008 [39] } & USA & Future pandemic strain & Multiple & 72 & - & - \\
\hline & & & Multiple + AV & 91 & 81 & 64 \\
\hline
\end{tabular}

Abbreviations: ILI influenza-like illness, $R_{0}$ basic reproduction number, Imperial/Pitt Imperial College and the University of Pittsburgh, UW/LANL University of Washington and Fred Hutchinson Cancer Research Center in Seattle and the Los Alamos National Laboratories, VBI Virginia Bioinformatics Institute of the Virginia Polytechnical Institute and State University

a Percentage reduction $=(($ Attack rate in the absence of intervention - Attack rate with intervention) $/$ Attack rate in the absence of intervention $) \times 100$. Unless otherwise stated, percentage reduction applies to the intervention group in the epidemiological studies and to the general population in the modeling studies ${ }^{\mathrm{b}}$ Single: Workplace social distancing (e.g., working from home, reduction in workplace contacts by $50 \%$ ); Multiple: Workplace social distancing and other nonpharmaceutical interventions; AV: Antiviral treatment and prophylaxis; VAC: Vaccination

'Outcomes are surrogates for influenza: Rousculp - Attended work with severe ILI; Kumar - ILI; Lee - Seroconversion to 2009 influenza A(H1N1)

${ }^{\mathrm{d}}$ Reduction in cumulative influenza attack rate in the workplace $=58 \%$

${ }^{e}$ Reduction in cumulative influenza attack rate in the workplace $=81 \%$

For studies modeling $\mathrm{R}_{0} \leq 1.9$, workplace social distancing measures alone (single intervention) showed a median reduction of $23 \%$ in the cumulative influenza attack rate in the general population (Table 1). Workplace social distancing measures combined with other nonpharmaceutical interventions showed a median reduction of $75 \%$ in the general population. Adding antiviral treatment and prophylaxis further reduced the influenza attack rate (median reduction $=90 \%)($ Table 1$)$.
Subgroup analysis reported in two studies indicated that the percentage reduction was higher in workplaces than in the general population (Table 1 footnote).

The modeling studies reported that percentage reduction in cumulative influenza attack rate in the general population declined with higher $R_{0}$ values (Table 1 ). The percentage reduction declined with increasing threshold for triggering interventions or with delayed implementation of interventions (Table 3). The 
Table 2 Risk of bias in epidemiological studies of workplace social distancing, 2000-2017*

\begin{tabular}{|c|c|c|c|c|c|c|c|c|c|}
\hline $\begin{array}{l}\text { First author, } \\
\text { year published }\end{array}$ & Outcome & Confounding & Selection & $\begin{array}{l}\text { Intervention } \\
\text { classification }\end{array}$ & $\begin{array}{l}\text { Intervention } \\
\text { deviations }\end{array}$ & $\begin{array}{l}\text { Missing } \\
\text { data }\end{array}$ & $\begin{array}{l}\text { Outcome } \\
\text { measurement }\end{array}$ & $\begin{array}{l}\text { Reported } \\
\text { results }\end{array}$ & Overall \\
\hline Rousculp, 2010 [27] & $\begin{array}{l}\text { Attend work with } \\
\text { severe ILI }\end{array}$ & Moderate $^{a}$ & Low & Low & Low & Low & Moderate $^{b}$ & Serious $^{c}$ & Serious \\
\hline Kumar, 2012 [28] & $\mathrm{ILI}$ & Serious $^{d}$ & Low & Moderate $e^{e}$ & Low & Moderate $^{f}$ & Moderate $^{b}$ & Low & Critical \\
\hline Lee, 2010 [29] & $\begin{array}{l}\text { Seroconversion to } \\
2009 \text { influenza } A(\mathrm{H} 1 \mathrm{~N} 1)\end{array}$ & Serious $^{d}$ & Low & Low & Low & Low & Low & Low & Serio \\
\hline
\end{tabular}

Abbreviations: ILI influenza-like illness

${ }^{*}$ Assessed using the Risk of Bias in Epidemiological Studies of Interventions (ROBINS-I) tool. Risk of bias for each domain is classified into four categories: low (study is comparable to a well performed randomized trial), moderate (study is sound for a non-randomized study but cannot be considered comparable to a well performed randomized trial), serious (study has some important problems), and critical (study is too problematic to provide any useful evidence on the effects of intervention)

${ }^{a}$ A nonrandomized study is rarely at low risk of bias for confounding

${ }^{b}$ Subjective outcome self-reported by participants who were aware of the intervention group

${ }^{c}$ Results for attending work with ILI symptoms of any severity are not reported

d Inadequate or no adjustment

Intervention status was determined retrospectively

fResponse rate was $56 \%$

percentage reduction also declined with lower compliance to workplace social distancing interventions (Table 4).

The percentage reduction in the peak daily attack rate was reported in five modeling studies (Table 5). These studies showed substantial effects in reducing the peak rate (median reduction for workplace social distancing alone $=45 \%$ ). The time to influenza peak was reported in one epidemiological and four modeling studies (Table 6). These studies reported later peaks with intervention compared to no intervention (median delay to peak for workplace social distancing alone $=6$ days).

\section{Discussion}

Epidemiological and modeling studies indicated that workplace social distancing reduced the overall number of influenza cases. It also reduced and delayed the influenza peak. The modeling studies reported that the reduction in influenza cases was more pronounced when workplace social distancing was combined with other interventions. However, the effectiveness was estimated to decline with higher $R_{0}$ values, delayed triggering of workplace social distancing, or lower compliance.

Droplets, and possibly aerosols, generated by coughs and sneezes are a major source of influenza transmission [42-45]. Social distancing in workplaces can decrease the risk of person-to-person influenza transmission by reducing droplet transmission that occurs within $3-6 \mathrm{ft}$ [43]. Workplace social distancing and other nonpharmaceutical or pharmaceutical interventions implemented together can act in complementary ways to reduce virus transmission $[3,46]$. Social distancing was estimated to be less effective for higher $R_{0}$ values. The lower effectiveness could be because social distancing may be less likely to reduce the effective reproduction number to below one if $R_{0}$ is higher [6]. The lower effectiveness with delayed triggering or lower compliance may be due to several factors. Delayed triggering of workplace social distancing precludes the opportunity to impact cases that have already occurred and represents a missed opportunity to diminish further transmission. Lower compliance increases the opportunity for person-to-person transmission.

This systematic review has several potential limitations. First, most of the included studies were based on modeling and few were in actual settings. Models can fill gaps when decisions must be made when there is a paucity of information [47]. However, more epidemiological studies are needed on social distancing in actual settings. Second, we did not assess the quality of the modeling studies. Input parameters used in simulation models include the population characteristics that describe exposure points (e.g., households, schools, workplaces); the population's behaviors that represent exposure frequencies (e.g., contact rates and durations); and disease transmission parameters $[15,48]$. There are few empirical studies on contact rates at workplaces [30]. No studies provided empirical information regarding the impact of workplace social distancing measures on changing workplace contact rates. Third, the studies included did not report the effects of workplace social distancing on two of our primary outcomes of interest (lost workdays, harms). The impact on lost workdays would represent the balance between potential work loss associated with social distancing (which can be mitigated by the ability to work from home) and sick days averted by reduction in influenza transmission and illness. One study reported that a lower proportion of Hispanic and African American workers than of white workers are able to work at 
Table 3 Percentage reduction in cumulative influenza attack rate in the general population, by threshold for triggering intervention, modeling studies, 2000-2017

\begin{tabular}{|c|c|c|c|c|c|}
\hline \multirow[t]{2}{*}{ First author, year published } & \multirow[t]{2}{*}{ Intervention $^{a}$} & \multirow[t]{2}{*}{ Threshold (\%) ${ }^{b}$} & \multicolumn{3}{|c|}{ Percentage reduction ${ }^{c}$} \\
\hline & & & $\mathrm{R}_{0} \leq 1.9$ & $\mathrm{R}_{0}=2.0-2.4$ & $\mathrm{R}_{0} \geq 2.5$ \\
\hline \multirow[t]{4}{*}{ Zhang, 2012 [31] } & \multirow[t]{4}{*}{ Single } & 0.02 & 18 & - & - \\
\hline & & 0.25 & 18 & - & - \\
\hline & & 1.5 & 18 & - & - \\
\hline & & 5.0 & 17 & - & - \\
\hline \multirow[t]{6}{*}{ Halloran-Imperial/Pitt model, 2008 [39] } & \multirow[t]{6}{*}{ Multiple + AV } & 0.0001 & 99 & 96 & 64 \\
\hline & & 0.001 & 99 & 95 & 64 \\
\hline & & 0.01 & 99 & 94 & 64 \\
\hline & & 0.1 & 97 & 88 & 62 \\
\hline & & 1.0 & 83 & 70 & 53 \\
\hline & & 10.0 & 31 & 27 & 23 \\
\hline \multirow[t]{6}{*}{ Halloran-UW/LANL model, 2008 [39] } & \multirow[t]{6}{*}{ Multiple + AV } & 0.0001 & 99 & 99 & 99 \\
\hline & & 0.001 & 99 & 99 & 99 \\
\hline & & 0.01 & 99 & 99 & 99 \\
\hline & & 0.1 & 99 & 99 & 98 \\
\hline & & 1.0 & 94 & 92 & 86 \\
\hline & & 10.0 & 57 & 54 & 47 \\
\hline \multirow[t]{6}{*}{ Halloran-VBI model, 2008 [39] } & \multirow[t]{6}{*}{ Multiple + AV } & 0.0001 & 96 & 89 & 67 \\
\hline & & 0.001 & 96 & 89 & 67 \\
\hline & & 0.01 & 96 & 89 & 67 \\
\hline & & 0.1 & 96 & 88 & 66 \\
\hline & & 1.0 & 91 & 81 & 64 \\
\hline & & 10.0 & 55 & 49 & 50 \\
\hline \multirow[t]{8}{*}{ Milne, $2008[34,40]$} & \multirow[t]{4}{*}{ Single } & Prior to first case & 28 & - & - \\
\hline & & 2 weeks after 1 st case & 27 & - & - \\
\hline & & 4 weeks after 1 st case & 25 & - & - \\
\hline & & 6 weeks after 1 st case & 19 & - & - \\
\hline & \multirow[t]{4}{*}{ Multiple } & Prior to first case & 94 & - & 95 \\
\hline & & 2 weeks after 1 st case & 94 & - & 89 \\
\hline & & 4 weeks after 1 st case & 86 & - & 29 \\
\hline & & 6 weeks after 1 st case & 73 & - & 1 \\
\hline \multirow[t]{3}{*}{ Milne, 2013 [35] } & \multirow[t]{3}{*}{ Multiple } & Immediately after 1 st case & 63 & - & - \\
\hline & & 2 weeks after 1 st case & 63 & - & - \\
\hline & & 4 weeks after 1 st case & 48 & - & - \\
\hline
\end{tabular}

Abbreviations: $R_{0}$ basic reproduction number, Imperial/Pitt Imperial College and the University of Pittsburgh, UW/LANL University of Washington and Fred Hutchinson Cancer Research Center in Seattle and the Los Alamos National Laboratories, VBI Virginia Bioinformatics Institute of the Virginia Polytechnical Institute and State University

a Single: Workplace social distancing; Multiple: Workplace social distancing and other nonpharmaceutical interventions; AV: Antiviral treatment and prophylaxis ${ }^{b}$ Threshold percent: Cumulative influenza illness attack rate in the general population that will trigger intervention

${ }^{c}$ Percentage reduction $=(($ Attack rate in the absence of intervention - Attack rate with intervention $) /$ Attack rate in the absence of intervention $) \times 100$

home [28]. This observation indicates the need to consider the potential for racial or ethnic disparities. Fourth, because the effectiveness of workplace social distancing would depend on many factors, including $\mathrm{R}_{0}$, timing of implementation, and compliance, it is difficult to estimate the likely magnitude of impact in a future pandemic. Finally, only one of the included studies represented a lower-income country setting [35]. The findings of our evidence synthesis may not be generalizable to lower-income countries that differ in demography and contact patterns. 
Table 4 Percentage reduction in cumulative influenza attack rate in the general population, by compliance with intervention, modeling studies, 2000-2017

\begin{tabular}{|c|c|c|c|c|c|}
\hline \multirow{2}{*}{$\begin{array}{l}\text { First author, } \\
\text { year published }\end{array}$} & \multirow[t]{2}{*}{ Intervention $^{\mathrm{a}}$} & \multirow{2}{*}{$\begin{array}{l}\text { Compliance } \\
\text { (\%) }\end{array}$} & \multicolumn{3}{|c|}{ Percentage reduction ${ }^{b}$} \\
\hline & & & $\mathrm{R}_{0} \leq 1.9$ & $R_{0}=2.0-2.4$ & $R_{0} \geq 2.5$ \\
\hline \multirow[t]{4}{*}{ Mao, 2011 [32] } & \multirow[t]{4}{*}{ Single } & 100 & 82 & 23 & - \\
\hline & & 90 & 61 & 20 & - \\
\hline & & 75 & 41 & 16 & - \\
\hline & & 50 & 22 & 9 & - \\
\hline \multirow[t]{4}{*}{ Milne, 2008 [34] } & \multirow[t]{4}{*}{ Single } & 100 & 28 & - & 7 \\
\hline & & 90 & 26 & - & 7 \\
\hline & & 75 & 25 & - & 5 \\
\hline & & 50 & 17 & - & 2 \\
\hline
\end{tabular}

Abbreviation: $R_{0}$ basic reproduction number

asingle: Workplace social distancing

${ }^{\mathrm{b}}$ Percentage reduction $=(($ Attack rate in the absence of intervention - Attack rate with intervention $) /$ Attack rate in the absence of intervention $) \times 100$

There were several strengths. We conducted a comprehensive search of the literature that focused on workplace social distancing. The studies included in our review assessed the effect of workplace social distancing measures alone or combined with other interventions, allowing assessment of the relative effectiveness of single and combination interventions.

To our knowledge, our systematic review is the first one that focuses on workplace social distancing. A previous systematic review of modeling studies published during 1990 to 2009 assessed the effectiveness of pharmaceutical (vaccines and antiviral agents) and nonpharmaceutical (case isolation, quarantine, personal hygiene measures, social distancing, and travel restrictions) strategies for pandemic influenza response [49]. This previous review, which was based on 19 articles (five of these articles included workplace closure and two included workplace social distancing), concluded that combination strategies increased the effectiveness of individual strategies. Other systematic reviews that have assessed the effectiveness of interventions in reducing pandemic influenza transmission did not examine workplace social distancing measures [50].

An increasing trend in the ability to telework aligns with recommendations for social distancing in a pandemic, but teleworking is less feasible for many occupations [51]. About 24\% of employed persons did some or all of their work at home in 2015, ranging from about 35\% in managerial and professional occupations to only $6 \%$ in production occupations. It is estimated that it is possible for $50 \%$ of the US workforce to telework at least partially [52]. Studies that examine feasible and acceptable workplace social

Table 5 Percentage reduction in peak influenza attack rate in the general population, modeling studies, 2000-2017

\begin{tabular}{|c|c|c|c|c|c|c|}
\hline \multirow{2}{*}{$\begin{array}{l}\text { First author, } \\
\text { year published }\end{array}$} & \multirow[t]{2}{*}{ Country } & \multirow[t]{2}{*}{ Influenza strain } & \multirow[t]{2}{*}{ Intervention $^{a}$} & \multicolumn{3}{|c|}{ Percentage reduction ${ }^{b}$} \\
\hline & & & & $R_{0} \leq 1.9$ & $R_{0}=2.0-2.4$ & $R_{0} \geq 2.5$ \\
\hline Zhang, 2012 [31] & Singapore & Not reported & Single & 28 & - & - \\
\hline Mao, 2011 [32] & USA & $\begin{array}{l}\text { Seasonal scenario } \\
\left(\mathrm{R}_{0}=1.4\right) \text { and a } \\
\text { pandemic scenario } \\
\left(\mathrm{R}_{0}=2.0\right)\end{array}$ & Single & 97 & 53 & - \\
\hline \multirow[t]{2}{*}{ Xia, 2013 [33] } & \multirow[t]{2}{*}{ China } & \multirow{2}{*}{$\begin{array}{l}2009 \text { Influenza } \\
\text { A(H1N1) pandemic }\end{array}$} & Single & 51 & - & - \\
\hline & & & Single + VAC & 91 & - & - \\
\hline \multirow[t]{2}{*}{ Milne, 2008 [34] } & \multirow[t]{2}{*}{ Australia } & \multirow[t]{2}{*}{ Pandemic strain } & Single & 39 & 25 & 18 \\
\hline & & & Multiple & 97 & 99 & 99 \\
\hline Milne, 2013 [35] & $\begin{array}{l}\text { Papua } \\
\text { New Guinea }\end{array}$ & Pandemic strain & Multiple & 91 & - & - \\
\hline
\end{tabular}


Table 6 Time to influenza peak, epidemiological and modeling studies, 2000-2017

\begin{tabular}{|c|c|c|c|c|c|c|}
\hline \multirow{2}{*}{$\begin{array}{l}\text { First author, year } \\
\text { published }\end{array}$} & \multirow[t]{2}{*}{ Country } & \multirow[t]{2}{*}{ Influenza strain } & \multirow[t]{2}{*}{ Intervention ${ }^{\mathrm{b}}$} & \multicolumn{3}{|l|}{ Days to peak } \\
\hline & & & & $\mathrm{R}_{0} \leq 1.9$ & $R_{0}=2.0-2.4$ & $R_{0} \geq 2.5$ \\
\hline Lee, 2010 [29] & Singapore & $\begin{array}{l}2009 \text { influenza A } \\
\text { (H1N1) pandemic }\end{array}$ & Multiple & $\begin{array}{l}\text { Peak later (unspecified) with } \\
\text { intervention }\end{array}$ & - & - \\
\hline Zhang, 2012 [31] & Singapore & Not reported & Single & Peak 1 day later with intervention & - & - \\
\hline Mao, 2011 [32] & USA & $\begin{array}{l}\text { Seasonal scenario }\left(R_{0}=1.4\right) \\
\text { and a pandemic scenario } \\
\left(R_{0}=2.0\right)\end{array}$ & Single & $\begin{array}{l}\text { Peak } 89 \text { days later with } \\
\text { intervention }\end{array}$ & $\begin{array}{l}\text { Peak } 18 \text { days later } \\
\text { with intervention }\end{array}$ & - \\
\hline Xia, 2013 [33] & China & $\begin{array}{l}2009 \text { influenza A(H1N1) } \\
\text { pandemic }\end{array}$ & Single & Peak 6 days later with intervention & - & - \\
\hline Milne, 2013 [35] & $\begin{array}{l}\text { Papua New } \\
\text { Guinea }\end{array}$ & Pandemic strain & Multiple & Peak 13 days later with intervention & - & - \\
\hline
\end{tabular}

Abbreviations: $R_{0}$ basic reproduction number

${ }^{a}$ For the modeling studies (Zhang [31], Mao [32], Xia [33], Milne [35]), time to influenza peak is reported for the general population

${ }^{\mathrm{b}}$ Single: Workplace social distancing; Multiple: Workplace social distancing and other nonpharmaceutical interventions

distancing strategies in a variety of work settings are needed to improve pandemic preparedness. Because contact patterns differ in different types of industries and workplaces, the impact of social distancing in various settings needs to be assessed. Further research is needed to facilitate development of higher-fidelity models of influenza transmission in the workplace for model-based evaluation of NPI effects in different industries. Cross-sectional epidemiological studies can be used to assess the prevalence of workplace social distancing measures, but this design is not optimal to assess effectiveness because of inherent biases [53]. Because randomizing employers or employees to social distancing or control arms may not be feasible, prospective cohort studies may provide the best available evidence on effectiveness. Employers that have implemented workplace social distancing measures could be compared to those that have not, particularly during a pandemic. However, attention should be paid to collecting data on potential confounding variables and using outcomes that are defined in an objective manner (e.g., laboratory-confirmed influenza illness, sensitive and specific case definitions using electronic medical records data).

Our findings have several implications. First, the effectiveness of workplace social distancing was estimated to decline with higher $R_{0}$ values. This finding has ramifications regarding the intensity of community mitigation measures that may be needed in atypical pandemics with higher $R_{0}$ values. Second, effectiveness declined with delayed triggering. The ability of local surveillance systems to accurately detect influenza circulation in the community to inform triggering decisions will depend on several factors, including the sensitivity and specificity of the case definition (laboratory testing of all ill patients may not be possible), the representativeness of the reported cases, and the completeness of reporting. Algorithms for estimating the total number of cases in a community based on cases detected by local surveillance systems, or use of proxy measures, may be needed to guide triggering decisions. Decision-makers should weigh the benefits versus disruptions of implementing workplace social distancing measures in the context of pandemic severity [46]. Third, effectiveness declined with lower compliance. Triggering social distancing too early can contribute to lower compliance because of intervention fatigue [54]. Finally, effectiveness was reported to be greater when workplace social distancing was combined with other nonpharmaceutical or pharmaceutical interventions. The findings underscore the importance for coordination between employers and state/local health departments to potentially enhance impact using a combination of measures.

\section{Conclusions}

Our systematic review shows that there are few epidemiological studies in actual settings. More research is needed to assess the effectiveness of social distancing measures in a variety of industries and work settings. The included epidemiological and modeling studies indicate that social distancing in nonhealthcare workplaces reduces the overall as well as the peak number of influenza cases. It also delays the influenza peak. The finding that reduction in influenza cases is more pronounced when workplace social distancing is combined with other nonpharmaceutical or pharmaceutical interventions highlights the importance of using a combination of measures to reduce the transmission of pandemic influenza. 


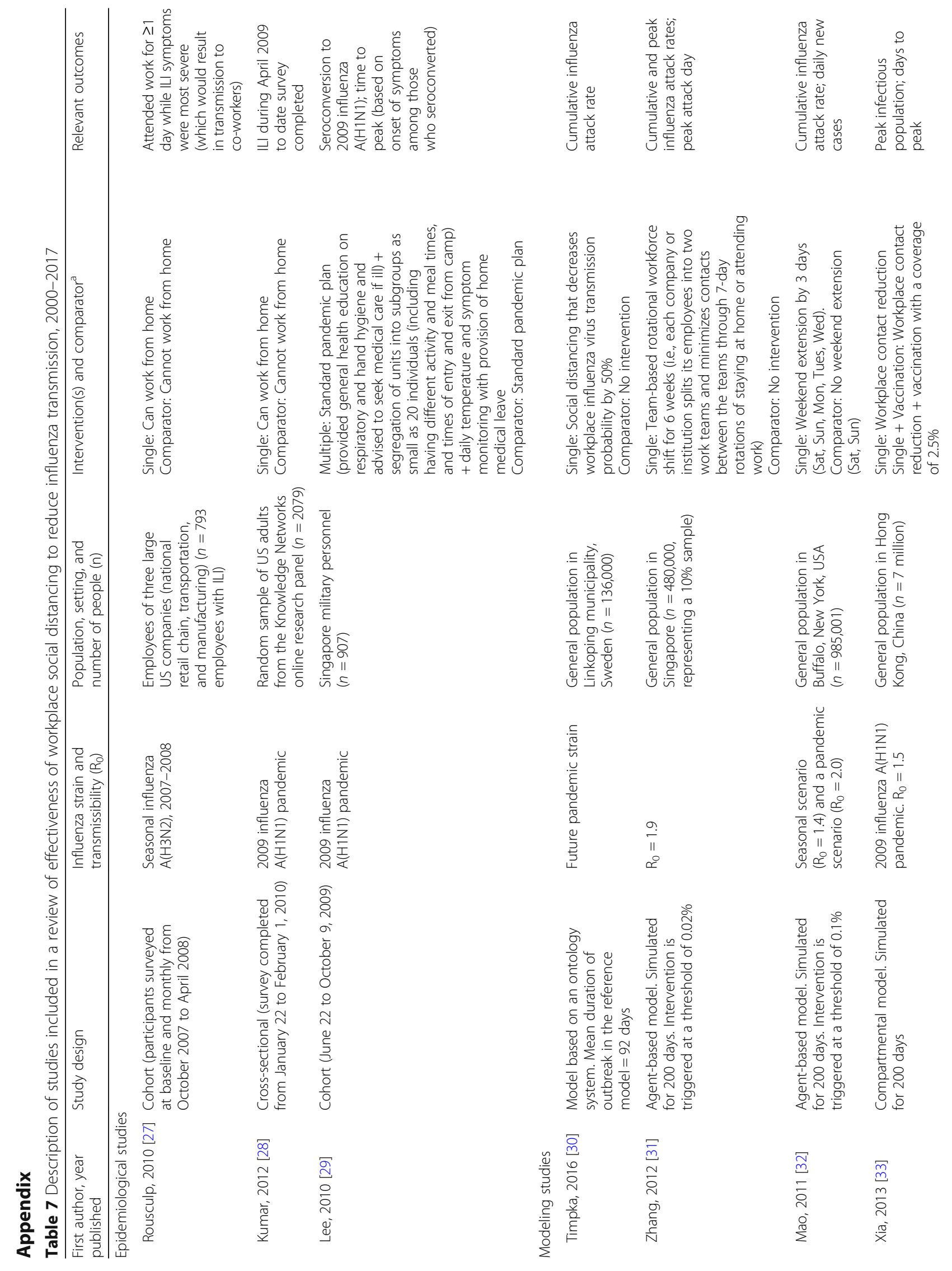




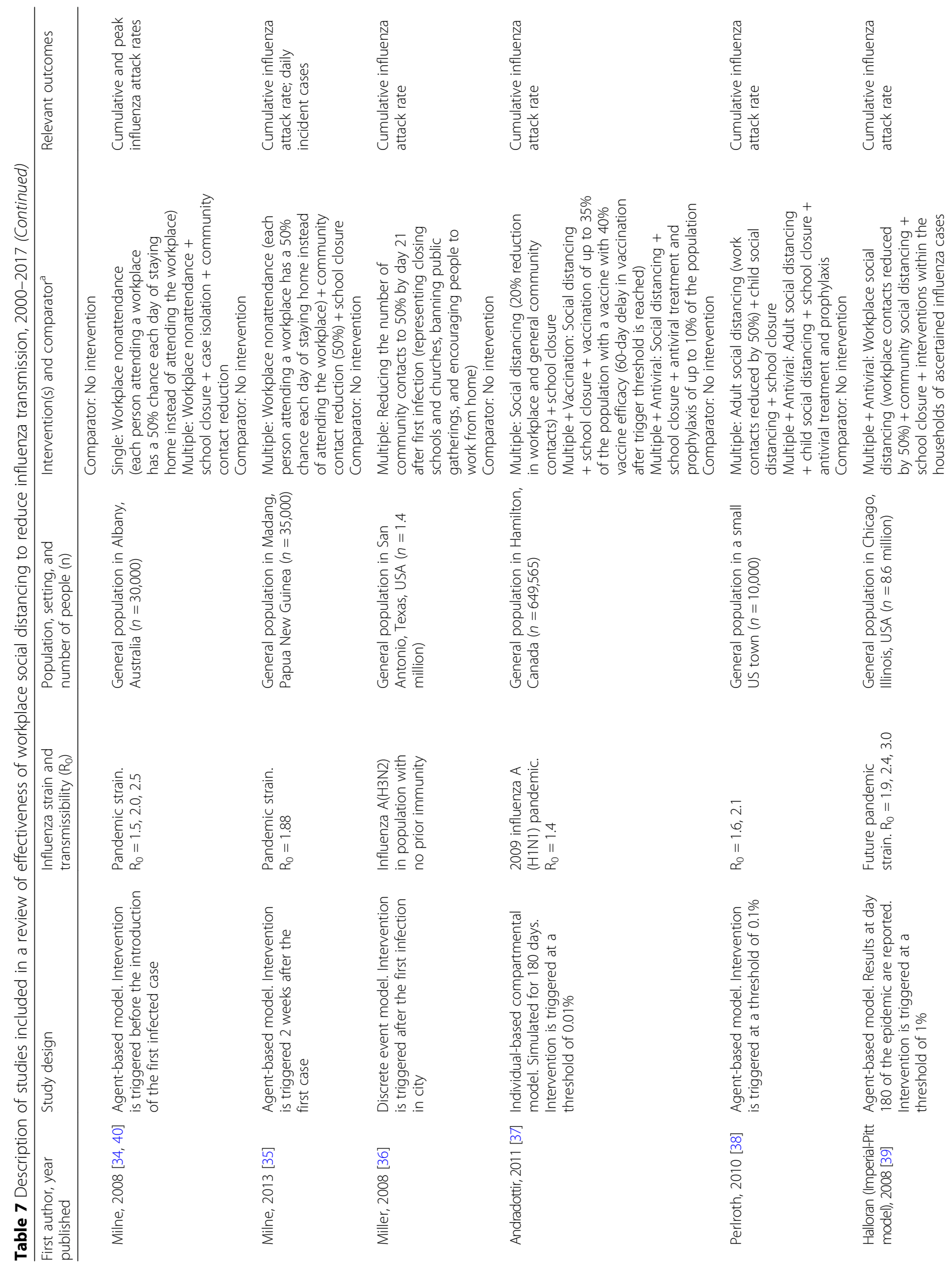


Ahmed et al. BMC Public Health (2018) 18:518

Page 11 of 13

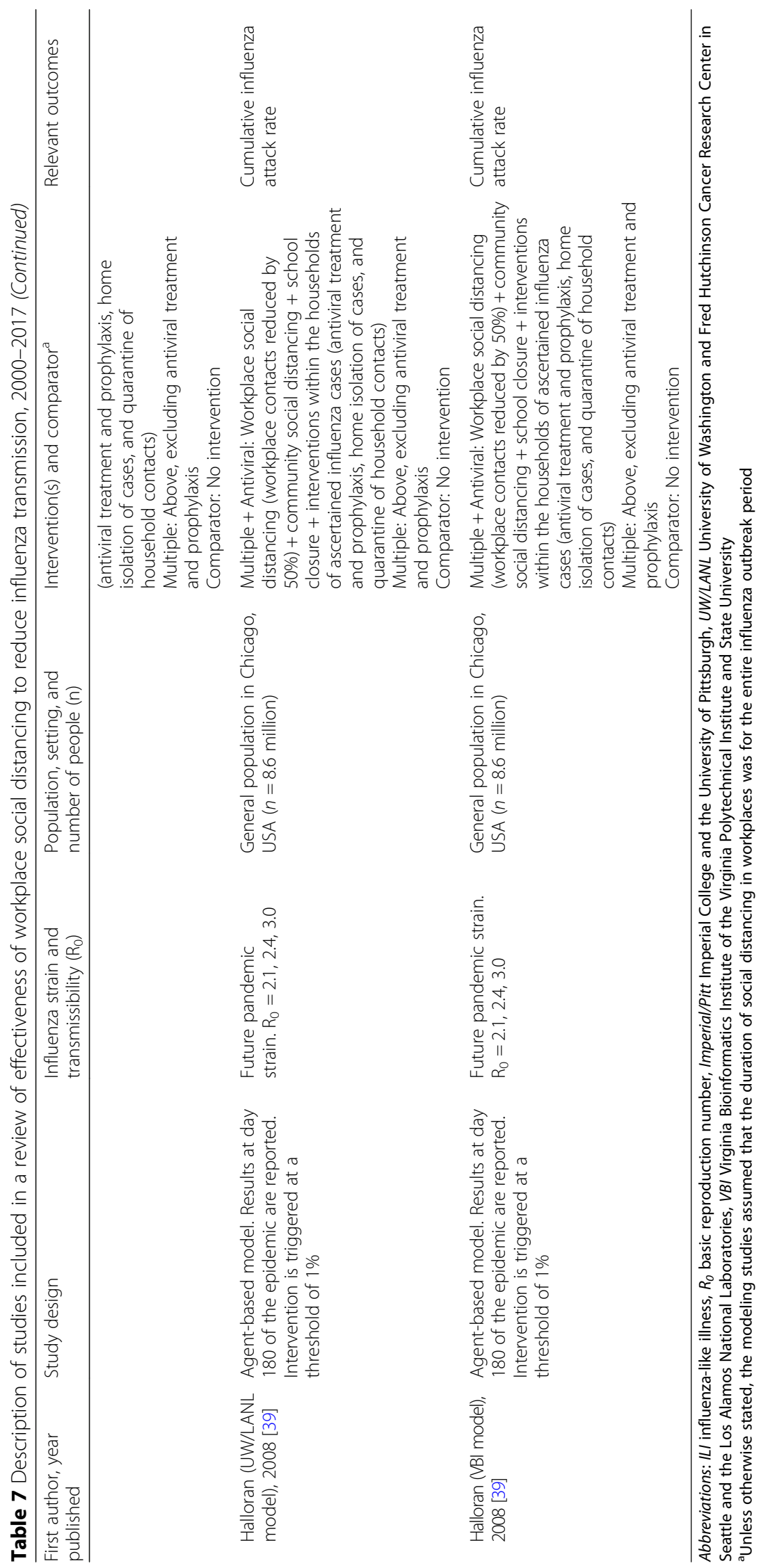




\section{Additional files}

Additional file 1: Table S1. PRISMA 2009 checklist. (DOC 63 kb)

Additional file 2: Table S2. Data for percentage reduction in cumulative influenza attack rate. (XLSX $13 \mathrm{~kb}$ )

Additional file 3: Table S3. Data for percentage reduction in cumulative influenza attack rate in the general population, by threshold for triggering intervention. (XLSX $14 \mathrm{~kb}$ )

Additional file 4: Table S4. Data for percentage reduction in cumulative influenza attack rate in the general population, by compliance with intervention. (XLSX $11 \mathrm{~kb}$ )

Additional file 5: Table S5. Data for percentage reduction in peak influenza attack rate in the general population. (XLSX $11 \mathrm{~kb}$ )

Additional file 6: Table S6. Data for time to influenza peak. (XLSX 9 kb)

\section{Abbreviations}

AV: Antiviral treatment and prophylaxis; CINAHL: Cumulative Index to Nursing and Allied Health Literature; ILI: Influenza-like illness; Imperial/ Pitt: Imperial College and the University of Pittsburgh;

NPI: Nonpharmaceutical intervention; PRISMA: Preferred Reporting Items for Systematic Reviews and Meta-Analysis; $\mathrm{R}_{0}$ : Basic reproduction number; US: United States; UW/LANL: University of Washington and Fred Hutchinson Cancer Research Center in Seattle and the Los Alamos National Laboratories; VAC: Vaccination; VBI: Virginia Bioinformatics Institute of the Virginia Polytechnical Institute and State University

\section{Acknowledgements}

The authors thank Joanna Taliano, librarian at the Stephen B. Thacker CDC Library, for her expert contribution to developing the syntax for the searches and conducting electronic database searches.

The findings and conclusions in this study are those of the authors and do not necessarily represent the official position of the Centers for Disease Control and Prevention.

\section{Availability of data and materials}

All data generated or analyzed during this study are included in this published study and its Additional files (see Additional files 2, 3, 4, 5 and 6).

\section{Authors' contributions}

FA participated in all steps of the research and wrote the first draft of the manuscript. NZ participated in screening records, data extraction, quality assessment of epidemiological studies, and revising the manuscript. AU participated in conceptualizing the review, resolving any questions about data extraction, and revising the manuscript. All authors read and approved the final manuscript.

\section{Author's information}

NZ is a fellow appointed through the Research Participation Program at the Centers for Disease Control and Prevention administered by the Oak Ridge Institute for Science and Education through an interagency agreement between the U.S. Department of Energy and the Centers for Disease Control and Prevention.

\section{Ethics approval and consent to participate}

Not applicable.

\section{Competing interests}

The authors declare that they have no competing interests.

\section{Publisher's Note}

Springer Nature remains neutral with regard to jurisdictional claims in published maps and institutional affiliations.
Received: 18 January 2018 Accepted: 11 April 2018

Published online: 18 April 2018

\section{References}

1. Reed C, Biggerstaff M, Finelli L, Koonin LM, Beauvais D, Uzicanin A, et al. Novel framework for assessing epidemiologic effects of influenza epidemics and pandemics. Emerg Infect Dis. 2013;19:85-91.

2. Meltzer MI, Cox NJ, Fukuda K. The economic impact of pandemic influenza in the United States: priorities for intervention. Emerg Infect Dis. 1999:5:659_ 71

3. Qualls N, Levitt A, Kanade N, Wright-Jegede N, Dopson S, Biggerstaff M, et al. Community mitigation guidelines to prevent pandemic influenza United States, 2017. Morbidity \& Mortality Weekly Report Recommendations \& Reports. 2017;66:1-34.

4. U.S. Department of Health and Human Services. Pandemic Influenza Plan: 2017 Update. 2017. https://www.cdc.gov/flu/pandemic-resources/pdf/panflu-report-2017v2.pdf. Accessed 12 Oct 2017.

5. World Health Organization. WHO Public Health Research Agenda for Influenza: 2017 Update. 2017. http://www.who.int/influenza/resources/ research/publication_research_agenda_2017/en/. Accessed 6 Mar 2018.

6. Jackson C, Mangtani P, Hawker J, Olowokure B, Vynnycky E. The effects of school closures on influenza outbreaks and pandemics: systematic review of simulation studies. PLoS One. 2014;9:e97297.

7. The Community Guide. Emergency preparedness and response: school dismissals to reduce transmission of pandemic influenza. 2012. https://www thecommunityguide.org/findings/emergency-preparedness-and-responseschool-dismissals-reduce-transmission-pandemic-influenza. Accessed $29 \mathrm{Mar}$ 2018.

8. Bureau of Labor Statistics, U.S. Department of Labor. The Employment Situation - August 2017. 2017. https://www.bls.gov/news.release/archives/ empsit_09012017.htm. Accessed 12 Oct 2017.

9. Edwards $\mathrm{CH}$, Tomba GS, de Blasio BF. Influenza in workplaces: transmission, workers' adherence to sick leave advice and European sick leave recommendations. Eur J Pub Health. 2016;26:478-85.

10. Ahmed F, Uzicanin A, Zviedrite N. Effectiveness of workplace social distancing measures in reducing influenza transmission: a systematic review. PROSPERO: International prospective register of systematic reviews. 2017. CRD42017065310. http://www.crd.york.ac.uk/PROSPERO/display_record. asp?|D=CRD42017065310. Accessed 12 Oct 2017

11. Liberati A, Altman DG, Tetzlaff J, Mulrow C, Gotzsche PC, loannidis JP, et al. The PRISMA statement for reporting systematic reviews and meta-analyses of studies that evaluate health care interventions: explanation and elaboration. PLoS Med. 2009;6:e1000100.

12. Sterne JA, Hernan MA, Reeves BC, Savovic J, Berkman ND, Viswanathan M, et al. ROBINS-l: a tool for assessing risk of bias in non-randomised studies of interventions. BMJ. 2016:355:i4919.

13. Centre for Reviews and Dissemination. Systematic Reviews: CRD's Guidance for Undertaking Reviews in Health Care. University of York. 2009. https:// www.york.ac.uk/media/crd/Systematic_Reviews.pdf. Accessed 13 Oct 2017.

14. Biggerstaff M, Cauchemez S, Reed C, Gambhir M, Finelli L. Estimates of the reproduction number for seasonal, pandemic, and zoonotic influenza: a systematic review of the literature. BMC Infect Dis. 2014;14:480.

15. Andradottir S, Chiu W, Goldsman D, Lee ML. Simulation of influenza propagation: model development, parameter estimation, and mitigation strategies. IIE Transactions on Healthcare Systems Engineering. 2014:4:27-48.

16. Carrat F, Luong J, Lao H, Salle AV, Lajaunie C, Wackernagel H. A 'smallworld-like' model for comparing interventions aimed at preventing and controlling influenza pandemics. BMC Med. 2006;4:26.

17. Ciofi degli Atti ML, Merler S, Rizzo C, Ajelli M, Massari M, Manfredi P, Furlanello C, et al. Mitigation measures for pandemic influenza in Italy: an individual based model considering different scenarios. PLoS One. 2008;3: e1790.

18. Ferguson NM, Cummings DA, Cauchemez S, Fraser C, Riley S, Meeyai A, et al. Strategies for containing an emerging influenza pandemic in Southeast Asia. Nature. 2005;437:209-14.

19. Ferguson NM, Cummings DA, Fraser C, Cajka JC, Cooley PC, Burke DS Strategies for mitigating an influenza pandemic. Nature. 2006;442:448-52.

20. Halder N, Kelso JK, Milne GJ. Cost-effective strategies for mitigating a future influenza pandemic with H1N1 2009 characteristics. PLoS One. 2011;6:e22087.

21. Mao L. Predicting self-initiated preventive behavior against epidemics with an agent-based relative agreement model. JASSS. 2015;18(4) 
22. Merler S, Jurman G, Furlanello C, Rizzo C, Bella A, Massari M, et al. Strategies for containing an influenza pandemic: the case of Italy. In: 2006 1st bioinspired models of network, information and computing systems, BIONETICS: 2006; 2006

23. Rizzo C, Lunelli A, Pugliese A, Bella A, Manfredi P, Tomba GS, et al. Scenarios of diffusion and control of an influenza pandemic in Italy. Epidemiol Infect. 2008;136:1650-7.

24. Roberts MG, Baker M, Jennings LC, Sertsou G, Wilson N. A model for the spread and control of pandemic influenza in an isolated geographical region. J R Soc Interface. 2007;4:325-30.

25. Xia H, Nagaraj K, Chen J, Marathe MV. Synthesis of a high resolution social contact network for Delhi with application to pandemic planning. Artif Intell Med. 2015;65:113-30.

26. Martinez DL, Das TK. Design of non-pharmaceutical intervention strategies for pandemic influenza outbreaks. BMC Public Health. 2014;14:1328.

27. Rousculp MD, Johnston SS, Palmer LA, Chu BC, Mahadevia PJ, Nichol KL. Attending work while sick: implication of flexible sick leave policies. J Occup Environ Med. 2010;52:1009-13.

28. Kumar S, Quinn SC, Kim KH, Daniel LH, Freimuth VS. The impact of workplace policies and other social factors on self-reported influenza-like illness incidence during the 2009 H1N1 pandemic. Am J Public Health. 2012;102:134-40.

29. Lee V, Yap J, Cook AR, Chen M, Tay J, Barr I, et al. Effectiveness of public health measures in mitigating pandemic influenza spread: a prospective sero-epidemiological cohort study. J Infect Dis. 2010;202:1319-26.

30. Timpka T, Eriksson H, Holm E, Stromgren M, Ekberg J, Spreco A, et al. Relevance of workplace social mixing during influenza pandemics: an experimental modelling study of workplace cultures. Epidemiol Infect. 2016;144:2031-42.

31. Zhang T, Fu X, Ma S, Xiao G, Wong L, Kwoh CK, et al. Evaluating temporal factors in combined interventions of workforce shift and school closure for mitigating the spread of influenza. PLoS One. 2012;7:e32203.

32. Mao L. Agent-based simulation for weekend-extension strategies to mitigate influenza outbreaks. BMC Public Health. 2011;11:522.

33. Xia S, Liu J, Cheung W. Identifying the relative priorities of subpopulations for containing infectious disease spread. PLoS One. 2013;8:e65271.

34. Milne GJ, Kelso JK, Kelly HA, Huband ST, McVernon J. A small community model for the transmission of infectious diseases: comparison of school closure as an intervention in individual-based models of an influenza pandemic. PLoS One. 2008;3:e4005.

35. Milne GJ, Baskaran P, Halder N, Karl S, Kelso J. Pandemic influenza in Papua New Guinea: a modelling study comparison with pandemic spread in a developed country. BMJ Open. 2013;3(3)

36. Miller G, Randolph S, Patterson JE. Responding to simulated pandemic influenza in San Antonio, Texas. Infection Control \& Hospital Epidemiology. 2008;29:320-6.

37. Andradottir S, Chiu W, Goldsman D, Lee ML, Tsui KL, Sander B, et al. Reactive strategies for containing developing outbreaks of pandemic influenza. BMC Public Health. 2011;11(Suppl 1):S1.

38. Perlroth DJ, Glass RJ, Davey VJ, Cannon D, Garber AM, Owens DK. Health outcomes and costs of community mitigation strategies for an influenza pandemic in the United States. Clin Infect Dis. 2010;50:165-74.

39. Halloran ME, Ferguson NM, Eubank S, Longini IM Jr, Cummings DA, Lewis B, et al. Modeling targeted layered containment of an influenza pandemic in the United States. Proc Natl Acad Sci U S A. 2008;105:4639-44.

40. Kelso JK, Milne GJ, Kelly H. Simulation suggests that rapid activation of social distancing can arrest epidemic development due to a novel strain of influenza. BMC Public Health. 2009;9:117.

41. Guyatt GH, Oxman AD, Kunz R, Woodcock J, Brozek J, Helfand M, et al. GRADE guidelines: 8. Rating the quality of evidence-indirectness. J Clin Epidemiol. 2011;64:1303-10.

42. Brankston G, Gitterman L, Hirji Z, Lemieux C, Gardam M. Transmission of influenza A in human beings. Lancet Infect Dis. 2007;7:257-65.

43. Bischoff WE, Swett K, Leng I, Peters TR. Exposure to influenza virus aerosols during routine patient care. J Infect Dis. 2013;207:1037-46.

44. Cowling BJ, Ip DK, Fang VJ, Suntarattiwong P, Olsen SJ, Levy J, et al. Modes of transmission of influenza B virus in households. PLoS One. 2014;9:e108850.

45. Yan J, Grantham M, Pantelic J, Bueno de Mesquita PJ, Albert B, Liu F, et al. Infectious virus in exhaled breath of symptomatic seasonal influenza cases from a college community. Proc Natl Acad Sci U S A. 2018;115:1081-6.
46. Barrios LC, Koonin LM, Kohl KS, Cetron M. Selecting nonpharmaceutical strategies to minimize influenza spread: the 2009 influenza a (H1N1) pandemic and beyond. Public Health Rep. 2012;127:565-71.

47. Fischer LS, Santibanez S, Hatchett RJ, Jernigan DB, Meyers LA, Thorpe PG, et al. CDC grand rounds: modeling and public health decision-making. MMWR Morb Mortal Wkly Rep. 2016;65:1374-7.

48. Prieto DM, Das TK, Savachkin AA, Uribe A, Izurieta R, Malavade S. A systematic review to identify areas of enhancements of pandemic simulation models for operational use at provincial and local levels. BMC Public Health. 2012;12:251.

49. Lee VJ, Lye DC, Wilder-Smith A. Combination strategies for pandemic influenza response - a systematic review of mathematical modeling studies. BMC Med. 2009;7:76.

50. Saunders-Hastings P, Reisman J, Krewski D. Assessing the state of knowledge regarding the effectiveness of interventions to contain pandemic influenza transmission: a systematic review and narrative synthesis. PLoS One. 2016;11:e0168262.

51. Bureau of Labor Statistics, U.S. Bureau of Labor. The Economics Daily, 24 percent of employed people did some or all of their work at home in 2015. 2016. https://www.bls.gov/opub/ted/2016/24-percent-of-employed-peopledid-some-or-all-of-their-work-at-home-in-2015.htm. Accessed 17 Feb 2017.

52. Global Workplace Analytics. Latest telecommuting statistics. 2017. http:// globalworkplaceanalytics.com/telecommuting-statistics. Accessed 12 Oct 2017.

53. Levin KA. Study design III: cross-sectional studies. Evid Based Dent. 2006;7:24-5.

54. Collinson S, Khan K, Heffernan JM. The effects of media reports on disease spread and important public health measurements. PLoS One. 2015:10: e0141423.

\section{Ready to submit your research? Choose BMC and benefit from:}

- fast, convenient online submission

- thorough peer review by experienced researchers in your field

- rapid publication on acceptance

- support for research data, including large and complex data types

- gold Open Access which fosters wider collaboration and increased citations

- maximum visibility for your research: over $100 \mathrm{M}$ website views per year

At BMC, research is always in progress.

Learn more biomedcentral.com/submissions 